\title{
The Curious Case of the Library Building
}

\section{Lawrence Lieberfeld}

A great many academic libraries have been built over the past twenty-five years, and a great deal has been written about their planning and construction. What is curious is the inconsistency between what is written and built, on the one hand, and the actual pattern of use of these buildings on the other. There is an abstract, almost mythic quality to the writings and to the widely utilized planning guidelines, as if there were no lessons to be learned by reviewing what happens after the buildings are occupied.

The result of ignoring experience in planning and designing academic libraries has been a substantial waste of resources. In turn, waste of plant resources can serve to diminish the operating funds available to libraries. Perhaps that prospect, in today's financial climate, can bring about more cost-effective planning and even a change in attitude toward capital budgeting.

In this paper, the initial sections deal with what the author has observed during many years at more than forty college and university libraries. There follow comments on established planning criteria and a brief review of the literature. The article concludes with a few questions and some very simple recommendations.

\section{THE UTILIZATION OF ACADEMIC LIBRARY BUILDINGS}

This article describes the levels of utili- zation of library buildings, as observed, monitored, and measured during the course of consulting studies. For the most part, these consulting engagements dealt with facilities planning, either for an entire campus or for the library alone. In some cases the focus of the study was on library staffing, systems, or finances, but included considerations of facilities data.

Of the forty-two studies, thirty-seven* incorporated systematic surveys of reader station utilization, and twenty-three included detailed analyses of book-stack utilization. Together, reader space and stack space constitute 80 to 90 percent of library space. These two elements are discussed in turn below.

\section{READER SPACE}

The number of reader stations (carrels or lounge chairs or segments of tables, etc.) is usually allocated via a formula or a ratio between the number of students at the institution and the presumed proper number of these reader stations. The ratios appear commonly in public university or regents' guidelines and in ACRL's Formula C. ${ }^{+}$Even institutions that do not officially utilize written guidelines are often influenced by knowledge of libraries planned on this basis or by generally held beliefs as to what ratios are appropriate.

On the face of it, the very concept of a formula applicable to large numbers or classes of colleges or universities is ques-

${ }^{*}$ Of these thirty-seven colleges and universities, thirteen are liberal arts colleges, seven are public or private universities, four are medical schools, and thirteen are other university libraries, e.g., business or science libraries. All but three of the liberal arts colleges would probably be classified as "strong" or "honors-oriented" in accord with Formula C of the ACRL Standards for College Libraries, 1975.

tFormula C of the ACRL Standards presents space planning criteria. Our understanding is that this formula is to remain unchanged, although a committee is currently reviewing other aspects of the document. 
tionable. Variables that influence the student's decision during the course of the day or evening to study or browse in the library include the nature of the academic program, the nature of the collection and the library's circulation policies, the character of student residences, the academic calendar, and the location of the library building. Why should this configuration of factors be the same for any two institutions?

If there were no other way to determine the number of seats required in an academic library, then a formula might be justified. However, there is a simple method that is both logical and useful in the great majority of cases. The essence of the problem is demand, that is, the number of reader stations that will satisfy the needs of students. This demand can be ascertained by a field survey of the actual utilization of tables, carrels, microreading stations, and so forth, except when the demand is equal or nearly equal to the supply of such facilities. Under such circumstances, the survey data might not be valid because students intending to use a reading area might be deterred by the apparent crowding. However, if the demand, as evidenced by periodic and systematic observation, is substantially less than the supply of the available number of stations, then the measure of that demand under normal circumstances constitutes a valid basis for planning.

Therefore, we ask those institutions for which we serve as consultants to conduct such a survey, using a simple one-page form. Each form covers one day's reader station utilization in one library building. The hours of the day and evening are arrayed at the left and across the page are columns representing the principal rooms or floor levels that provide reader stations. Further detail can be incorporated in the form, e.g., the distinction between carrels and tables or detailed data on index tables or microreading stations. The demand can be expressed both as a percent of enrollment and as a percent of available reader stations. The surveys typically run for three weeks. Thus, if the library were open for ninety hours per week, there would be 270 counts of readers using the facilities. Results of the surveys are in table 1 , based on the single hour when the most reader stations were occupied.

Various objections can and have been made as to the validity and significance of these data. For example, the time of year is important. We usually ask the librarian what time of year generates the maximum load. Responses vary; some mention the week before semester examinations, some an earlier week, when term-paper activity is presumed to be at peak. Although our surveys obviously do not always coincide with the perceived peak periods, we try to adjust the results accordingly. In some instances, we have had the opportunity to come back for a second survey at a later point in the school year.

The forms are filled out by library personnel, who make the rounds and count the number of seated readers once per hour. In a few cases, security personnel were assigned to this task, in other cases, work-study students, and in many instances, regular employees.

Another comment sometimes made by librarians is that current data do not take account of the impact that can be made by a new building - that the quality and amenities of a projected facility will attract students who do not utilize the existing building. We have found this to be the case only rarely. As the principal generator of library use is the academic program, there is no significant reason why a change in the library's physical environ-

TABLE 1

RESULTS OF THE SURVEYS

\begin{tabular}{lcc}
\hline & $\begin{array}{c}\text { Peak Use as Percent } \\
\text { of Available Stations }\end{array}$ & $\begin{array}{r}\text { Peak Use as Percent } \\
\text { of FTE Enrollment }\end{array}$ \\
\hline Liberal arts colleges & 33.8 & 10.6 \\
Universities & 44.0 & 5.1 \\
Medical schools & 53.8 & - \\
Other & 55.6 & - \\
\hline
\end{tabular}


ment will modify the pattern of use.

It is worth recalling that we are assuming that libraries should be planned to accommodate peak demand for reader stations. The median rate of utilization in the studies cited was typically $50-70$ percent of the peak, even when weekend counts were excluded.

How typical of academic libraries are the conditions revealed in these studies? Obviously, we cannot say with certainty, but our belief, based on an extensive, nationwide higher-education consulting practice, is that they are entirely typical. Librarians may not agree and are often defensive on this issue. If the librarian expects use of reader stations to reflect ACRL's Formula C or state planning guidelines, he or she may feel guilty about or unwilling to accept lower utilization rates. The problem is not in the libraries but in the formulas and guidelines.

\section{SPACE FOR THE COLLECTIONS}

The principal issue to be dealt with under this heading is the number of bound volumes (books and bound periodicals) that may appropriately be housed per square foot in the stack space of an academic library. One might expect that general agreement on such a number might be possible. But for various reasons, the number has been elusive, and the many articles written on the subject have not been based on adequate data. Our contention is that more books may be housed per square foot than is specified in the ACRL formula and the state guidelines.

The discussion will be limited to bound volumes, which occupy approximately 75 percent of the collection space in university libraries and a somewhat greater proportion in college libraries.

It is important to understand the variables that, in concert, determine the number of volumes that can be accommodated per square foot of floor space.

1. The size of the average book in the collection is obviously a significant factor. Most of the controversy over the question
How big is a book? relates to the thickness of the volume, but the other dimensions are also significant. Our surveys provide information on about 9 million bound volumes distributed among thirteen institutions. The average thickness varies; for all 9 million volumes the average thickness is almost exactly 1.33 inches or $1 / 9$ of a linear foot. It would be reasonable to assume that the higher the proportion of bound periodicals in the collection, the thicker the average volume. Yet the medical school libraries in our surveys conformed closely to the average of 1.33 inches.

Information on the thickness of volumes in academic libraries has not been prominent in the literature. Metcalf, in $1965,{ }^{1}$ refers only to architects Wheeler and Githens' measurements of the Brown University library volumes prior to World War II. He concludes that working capacity should be equated with six volumes per linear foot. We are convinced that seven volumes per foot is a proper average for planning collections space. *

2. Less commonly examined is the width of the base of the book-stack unit. We have found virtually no instances where we could not recommend bases $16^{3 / 4}$ inches in width, except for oversized books. The prevailing use of $20^{3 / 4}$-inchwidth bases, or even wider fixtures, is counterproductive.

3. The width of the aisle is a controversial subject. For functional purposes, i.e., circulation of patrons, employees, and book trucks, a 30 -inch aisle can be recommended, as opposed to aisles of 36 to 38 inches, which are noted in certain reference works, such as Architectural Graphic Standards. The situation has become muddled recently by the 1980 ANSI standard, ${ }^{2}$ which calls for 36 -inch passages to accommodate wheelchairs. These standards have the force of law for public university construction in many jurisdictions and also are incorporated in Section 504 of the Rehabilitation Act. The ANSI standard appears to impose a substantial and unnecessary penalty on colleges and univer-

${ }^{\star}$ For a $3{ }^{\prime \prime}$ " (nominal) shelf: $1.33^{\prime \prime} \times 21$ volumes $=27.9^{\prime \prime} ; 27.9^{\prime \prime} / 35.0^{\prime \prime}=79.8 \%$ or, say, $80 \%$ of absolute capacity. 
sities that are planning additions or new libraries and serves no useful purpose. The better way to provide for the patron in a wheelchair is via a page. In many cases, the wheelchair user will not be able to reach the top or bottom shelves, even though he may be able to traverse the aisle.

4. The last variable is the relationship between working and absolute capacity of the shelf, usually expressed as a percentage. We believe defining work capacity as 80 percent of absolute capacity is reasonable (Metcalf suggests 84 percent). The working-capacity concept implies that more space will be available when, say, 80 percent of the existing shelving is filled. Many librarians do not have this kind of implied confidence in their institutions, so that using a lower percentage to express working capacity represents a kind of hedge against the uncertain future. However justifiable such a position may be strategically, it does not reflect book-stack management requirements.

When the survey data and observations described above are combined, it can be demonstrated graphically and arithmetically that 19.1 volumes per square foot can be accommodated, based on 8-inch (nominal) shelves, 7 in height, 24-feet-long stack ranges, and 36 -inch aisles. * If we then factor in Metcalf's figures on the incidence of oversize books, the number of volumes is reduced to 18.8. Even if we also make an allowance for possible inefficiencies in architectural arrangements, the least productive outcome we can reasonably expect, in new buildings or additions, would be 17 volumes per square foot. In renovating old buildings one might be limited to 15-16 volumes per square foot or even less, if significant architectural aberrations are present.

We have found that inefficient bookstack layouts are very common, so that 12.5 volumes per square foot can be, but certainly need not be, the result. For example, we have seen on several occasions columns 24 feet on centers with ranges spaced 6 feet 0 inches on centers. Capacity could be increased by 25 percent by adding one more range per structural bay, resulting in 4 feet $91 / 2$ inches center to center spacing of the ranges, substantially more than adequate.

\section{GUIDELINES AND FORMULAS}

Reference has been made earlier to guidelines and formulas; these planning tools have had status and widespread use in library and academic circles for many years, at least thirty years to this writer's knowledge. Yet I have never seen, despite many inquiries, any data or validation from either the state boards of regents, the ACRL, or any other library organizations. ${ }^{3}$ The regents' staffs usually cite the ACRL as the source of their planning criteria.

On the reader station issue ACRL Formula $C$ calls for ratios between $1: 4$ and $1: 3$, representing reader stations: FTE enrollment. The smaller ratio is applied to "colleges wherein less than 50 percent of the FTE enrollment resides on campus," and the greater ratio is to be used for the "strong, liberal arts, honors-oriented college." Our data suggest that (a) the $1: 4$ ratio is excessive and wasteful and (b) the distinction between the two kinds of institutions does not have an analog in the degree to which students use reader stations. Perhaps the "strong" liberal arts college has better residential accommodations; we are convinced that the primary locus of study is the student's residence, in virtually all institutions.

The public university or board of regents' guidelines generally specify the 1:4 ratio, but some calculate on the basis of 1:3 for graduate students, without consideration of whether graduate students are being accommodated in laboratories or elsewhere in their departments. Some add dedicated, enclosed carrels for a percentage of the faculty, irrespective of the faculty office situation on campus. We have usually found that faculty carrels are the least utilized of all reader stations. Our surveys of reader stations encompass all

\footnotetext{
*This discussion does not apply to the reference collection, where fewer volumes per square foot can be accommodated.
} 
users: students, faculty, and visitors.

On the planning of book-stack space, instead of 17 volumes per square foot in new buildings, 12.5 volumes is the most commonly proposed figure. Metcalf demonstrated the feasibility of 15 volumes per square foot, and there is even more reason to avoid waste now than in 1965 . The ACRL stipulates 10 volumes per square foot for the first 150,000 volumes and then a graduated scale until, for holdings above 600,000 volumes, 14.3 per square foot are allowed. Thus, for a library of $500,000 \mathrm{vol}$ umes the recommended average volumes per square foot would be 11.2.

The rationale for the graduated scale is unclear. Why should the area per bound volume be different for a library with 150,000 volumes on one floor than for a library with 900,000 volumes on six floors?

For the remaining categories of space, Formula $\mathrm{C}$ and the state guidelines are at least as spendthrift. The ACRL and many of the states stipulate that "other" space, that is, space for the library functions other than collection space and reader space, should amount to 20 percent of the entire net area of the building. We doubt that such a condition exists and are confident that there is no justification for it, except perhaps for some library with a very distinctive activity pattern, such as a rare book facility. In fact, estimating other space (the most important single category in the "other" configuration is space for library employees) as a percent of collection space is irrational. For example, a college with a collection of 500,000 volumes would generate more "other space" than a college with 250,000 volumes, according to Formula C. Yet the college with the smaller collection may be accessioning at a higher rate and, therefore, maintaining a larger staff. The larger collection may simply be a function of the age and history of the institution.

\section{AN OVERVIEW OF THE LITERATURE}

The subject of physical planning criteria has not been dealt with extensively by any of the authors of the several facilities planning manuals for libraries except Metcalf. Following Metcalf's 1965 work, Ralph
Ellsworth published in 1973 a Planning Manual for Academic Library Buildings. One chapter deals with space standards; however, Ellsworth does not propose standards based on his own direct experience as a librarian and consultant. Instead, he cites the planning criteria utilized by a number of sources (including this author). He expresses a number of cautions concerning standards and formulas.

Ellsworth Mason, in Mason on Library Buildings (1980), devotes only a few lines to space planning. $\mathrm{He}$ calls for seating 20 percent of the students at one time in residential institutions, 10 percent elsewhere. For shelving, his specification equates with about 14 volumes per square foot.

Aaron Cohen, in Designing and Space Planning for Libraries (1979), devotes much more space to furnishings, mechanical and electrical equipment, and design features than to determining the size of the building. One of his examples specifies 17.5 volumes per square foot, although that example is based on 5 feet 0 inches center to center book-stack range spacing.

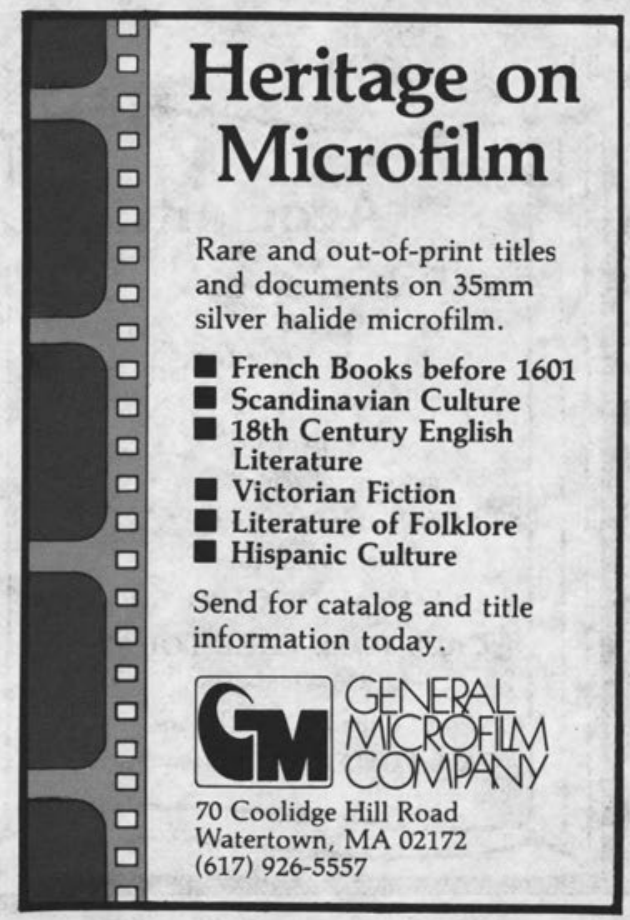


He does not deal with the determination of the number of reader stations.

It is fair to say that the literature does not provide information on planning either reader or stack space that is derived from institutional experience.

\section{CONCLUSIONS}

What does it all mean? Are Formula C and the guidelines serious attempts to express functional requirements? Are they simply bargaining chips to be used in the endless game of capital budgeting? Do they express the values of the institution or only of the library? Unlike the ACRL's Formulas A and B, which are designed to, but rarely do impact the institution's operating budget, Formula $\mathrm{C}$ and the associ- ated guidelines have a strong influence on the funding process and its outcomes.

What is the remedy? Simply eliminate Formula $\mathrm{C}$ and the guidelines. There is no reason why the ACRL cannot content itself with the kind of statement of general principles concerning facilities that is used by the ARL. In place of the guidelines let each institution develop library building programs on the basis of its own needs, without any predetermination or artificial assumptions hovering over the process.

It seems to us that the time has come when the "more is better" philosophy of physical planning in higher education should be abandoned. It is time to recognize that buildings are liabilities as much as they are assets.

\section{REFERENCES}

1. K. D. Metcalf, Planning Academic and Research Library Buildings (New York: McGraw-Hill, 1965).

2. American National Standards Institute A117.1-1980.

3. The ARL Standards for University Libraries (1979) do not quantify physical planning criteria, although reference is made to Metcalf, Planning.

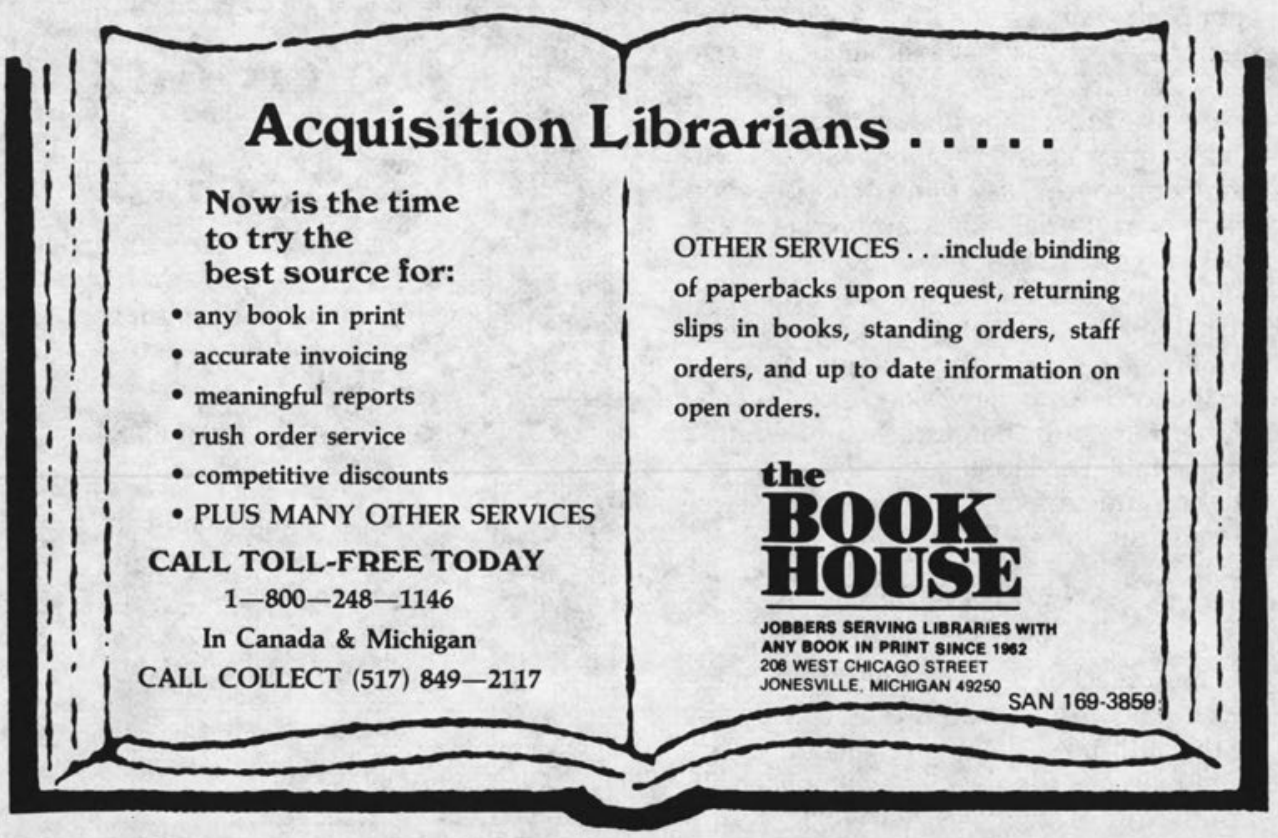

